\title{
The Influence of Buddhism on Qigong's Paintings
}

\author{
Ying Shi \\ College of Literature and Journalism \\ Sichuan University \\ Chengdu, China
}

\begin{abstract}
Due to family edification, Qigong's love for painting has been cultivated at an early age. He has written many poems and drawn many paintings. However, in his later years, his writings were much more famous than his paintings. As a result, the academic community paid less attention to his paintings. This paper intends to start with the influence of Buddhism on his painting and discuss it in three aspects: first, Qigong's painting experience and his unique way of combining Zen and painting; secondly, his painting view that interlinks Zen thought and the Zen art; the influence of Buddhism on his painting evaluation and painting creation.
\end{abstract}

Keywords-Qigong; Buddhism; paintings

\section{INTRODUCTION}

Qigong said in one of the poems on the peach paintings: "it was said that the monk Dao En was not only proficient in Zen, but also excellent in painting."[1] In the poem, he highly praised that monk Dao was not only good at Zen but also had great accomplishments in paintings. From this poem, we can see that Qi Gong thinks that painting and Zen are connected with each other, and they are each other's representations. However, there is little research on the relationship between his painting and his understanding in Zen, so this paper tries to study on it.

\section{EXPERIENCES IN PAINTING AND RELIGIOUS BELIEF}

According to Qi Gong, he was from the Manchu royal family and was the ninth generation of Yong Zheng. His painting originates from the atmosphere of his family and his grandfather Yu Lon was good at painting. In Qi Gong's Oral Expression of History, he says: "he (Yu Long) always showed me his painting. I still vividly remember the scene and feeling: he found a piece of paper, or a small fan, without any special arrangement, let alone a manuscript, a few strokes here, a few strokes there, and soon a landscape or a pine - bamboo was completed. At that moment, I keep my eyes wide open, watching. The surprising and admiring expression, like all little children watching a magic show, expressed how he wondered where the living man comes from. In my little heart, I felt it was the most fascinating and mysterious skills. So, I had the idea of becoming a painter at a young age." [2] By edification from this, Qi Gong began formal painting learning at an early age. ([3] see "Fig.1) "From about fifteen to twenty-five, I had the privilege of meeting some of the most famous artists, poets, scholars of the time, such as Mr. Jia Xi-min, Mr. Wu Jingting, Mr. Dai
Jiangfu, Mr. Pu Xinyu, Mr. Pu Xuezhai, and Mr. Qi Baishi. And I have formally worshiped some of them as my teachers. Under their instruction, the knowledge and skills lay the foundation for what I later mastered." [4]With his father's early death and his family's increasingly difficult financial situation, Qi Gong had made a living on selling paintings. He recounted: "At that time, I didn't finish high school. I didn't have a job. I can barely make a living by teaching at some schools temporarily. Now and then I sell some paintings to make more money." [5]Qi Gong also taught at the department of fine arts in Fu Ren School. When he transferred to a teacher of Chinese, he still did not give up painting creation and research. In Qi Gong's oral expression of history, he said: "My love for painting never changed. Around the time of the liberation, my painting reached the highest level in my life and had a considerable impact in the national painting circle... During $1951 \sim 1952$, the ministry of culture had also held a Chinese painting exhibition in the North Sea park. And I took out my four best exhibitors."[6] Unfortunately, due to the painting, Qi Gong was designated as the right wing by the Chinese academy of painting in 1958 "Once bitten, twice shy", from now on, Qi Gong is always scared about painting. What's more, his writings later were far better than his paintings, fewer and fewer people were paying attention to his paintings. As Huang Miaozi says: "In the work of Mr. Qi, the landscape, water, orchid and bamboo are all exquisite, but he seldom does such drawings. Because merely in the area of calligraphy, he has tasted the world's joys and sorrows; If he's a painter, what will he be? " [7]

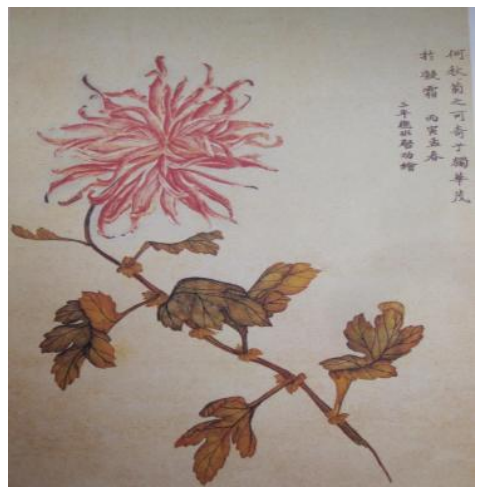

Fig. 1. Qi Gong's "chrysanthemum" in 1926, in the paper for Chinese paintings.

In fact, painting is an important part of Qi Gong's studies. $\mathrm{He}$ wrote in the "Autonomous Proposition for Imitation of Zheng Banqiao's Orchid and Bamboo": "Think back to those 
days, I was at a young age, ambitious and proud, I do not Zheng Banqiao was a thing. Now I am old, I begin to understand and truly admire Zheng Banqiao. His paintings are as classic as Lisao of Qu Yuan." [8]This poem is a true portrayal of the painting experience of Qi Gong's life. When he was young he was complacent. And only when he was old did he understand the true meaning of painting. The orchid and bamboo painted at the time are nothing more than a reflection of mood fluctuations. The traits of "Lisao" in Qi Gong poem is inseparable from his religious belief. For family reasons, Qi Gong formally became a member of the Lamaism in the lama temple at the age of three. [9] Buddhism's unique way of looking at the world had a great impact on him, and it is very appropriate for his disciple $\mathrm{Li}$ Shan to call him "Can Hezi". Therefore, Qi Gong often uses Zen to express the artistic state. In his book on the relationship between poetry, painting and calligraphy, he said: "By exploring the relationship between poetry, painting and calligraphy, we can understand the previous versions of 'poetic Zen', 'book Zen' and 'painting Zen'. The character of Zen is certainly too abstract. But in terms of poems, books and paintings that are not easily explained, the usage of Zen is more effective to generalize than using complex examples." [10]Thus, it can be seen that the art thought of Qi Gong and his religious thought are integrated and interacted with each other.

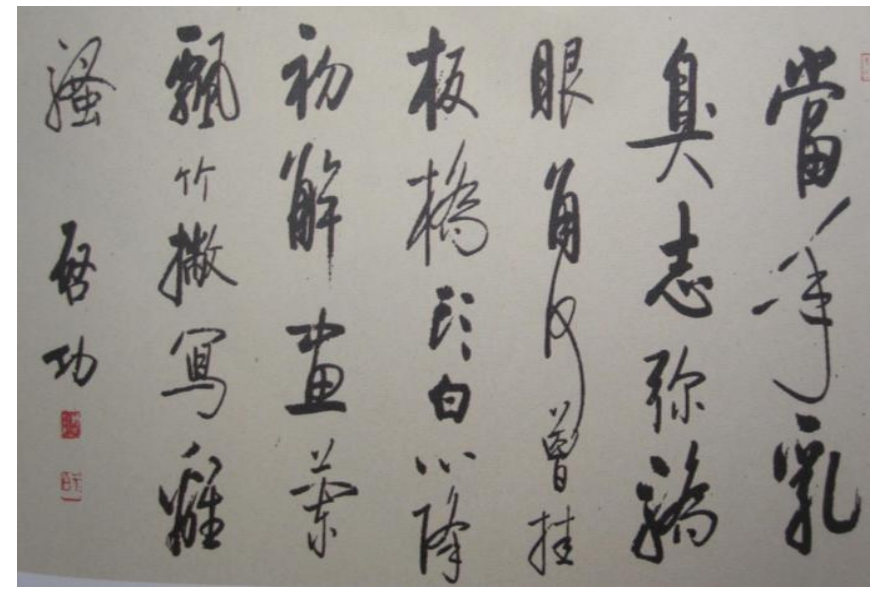

Fig. 2. Qi Gong's “Autonomous Proposition for Imitation of Zheng Banqiao's Orchid and Bamboo”.

In short, as a result of family education, Qi Gong began to like painting at a very young age and received long-term learning and training of techniques. Although it was interrupted after liberation, his deep love for it was not interrupted. At his old age, his paintings are less famous than his writings, so the academic community has little research on his paintings. But his painting was part of his academic career, and his paintings are merged with Zen. Therefore, if we want to understand the connotation of his painting, we must further discuss the Buddhist thoughts of Qi Gong.

\section{ARTISTIC CONCEPTION OF ZEN AND ARTISTIC INSPIRATION OF PAINTING}

In terms of Zen, Qi Gong was a student of Chen Yuan and has a lot of study on it. In his poem the 1,500th anniversary of Shaolin temple, he said: "the Pudhi Dharma came to Tai city on reed leaf but did not reach a tacit understanding with each other. Later, he went to north to the Shaolin Temple and faced to the wall and meditated. Then the sixth generation Hui Neng has been accepted by his ancestor and take over the power, he travelled far away from his home to avoid Shen Xiu's persecution. Buddhism is a land of peace. Why do we have wars? It's because two classics called Leng Gammon and Diamond sutra. Hui Neng knows no words but received the acceptance of his ancestor. De Shan bastinadoed his disciple to hand down his thought. Nan Quan did not grudge with killing a cat to break down his disciple's confusions about the appearances of things... The monks should do more study on Prajna Paramita and pay less attention to how much money one has got. [11]Qi Gong has generalized the history of Zen in his poems. From Dharma crossing a river on reed's leaf, to Desha bastinadoing his disciple, Nan Quan killing the cat to express his thought, and to the one thousand year's spreadings later, Qi Gong concluded that we need to study more prajna paramita. For the unique dharma system of Zen, he said in the act of Zen: The essence advocated by Zen is highly focused on the core concept. If you agree with each other in a word, you can understand its essence, which cannot be understood by laymen. However, the language of the core idea often has a lot of fans. From the books on Zen, there are similarities as well as inconsistencies.

If the Zen language used in the poems is properly, it will add color to the texts. In the books handed down by the ancient masters, there are sometimes a few sentences, many of which are concise and clever in language. Unfortunately, the source is very difficult to verify [12] 


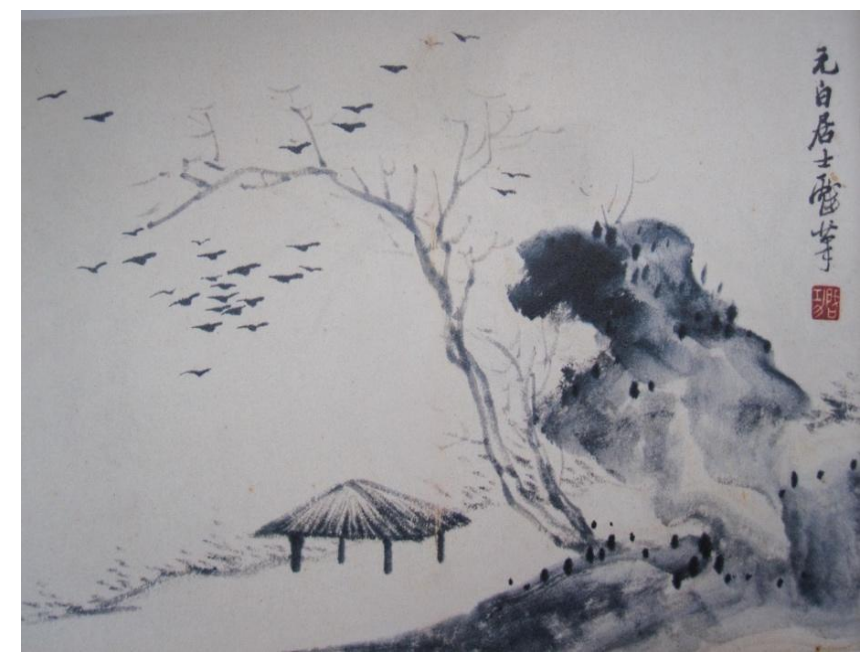

Fig. 3. Qi Gong's "Yuan Bai Ju Shi's freehand painting".

In this paper, the Buddhist monk $\mathrm{Pu} \mathrm{He}$ was a monk in Yunnan in the late Ming and early Qing dynasties. Though he was a monk, he never explained Buddhism publicly but only entertained himself with writings and paintings. He never talked about affairs of human life. It was described in the book that: "when it touched the key point, I can solve my confusions in half of my life." It pointed out that the mysterious sentences in Zen were the key to understand the Buddhism. There are few words but are targeted to get people awaken. If it can be used appropriately, it will greatly enrich the poems. What's more, Qi Gong thought that most monks are good at writings and paintings. In his poem Remarks at a calligraphy exhibition of Su Shipeng and Ono Gishi: "Monks are masters of calligraphy and painting, which is true from ancient to modern times." [13] Paintings and Zen are essentially connected. In the poem An Accidental Gift it was said that: "the poets' interest makes the mountains and forests meaningful. A calligrapher wrote in conjunction of the nature and can understand the true meaning of Buddhism in a word. The art in normal life and the principles of the Buddhism are connected originally." [14]Qi Gong uses Zen as a metaphor to explain the drawings to express the principles beyond words. In the "to herd the cows in the snow without a mark, archaic and lovely": "Every time a Zen Buddhist monk says a key sentence, he uses the water buffalo as a metaphor. The painter wanted to draw a good picture, he often drew a quiet mountain pond." [15]The buffalo is a famous case in Buddhism. "Fu zhou Cao Shan Yuan Zheng master's quotations" said: "when Nan Quan was ill, one asked him: 'where will a monk go after death?' Quan said: 'I will go to Tan Yue's house down the mountain to be a buffalo." [16]It refers that the ordinary things are often used by Buddhists to compare the abstract Buddhist doctrines, just as the painter often loves painting the quiet place of like forests and ponds. In "Poems in Hanshan Temple in Suzhou": "The Buddha used the moon as a metaphor in his teaching of the general idea of Buddhism to his disciples. Poets can write good poems and sentences through hearing the bell." [17]The moon is often used as a metaphor in Buddhism. The so-called "as long as there is water in the river, the river can reflect the moon" refers that the Buddhism exists in all things, and Buddhism uses the month to let disciples understand this truth. And the realm of poetry lies in the pursuit of being meaningful, like the sound of the bell as a lingering aftertaste. So are the paintings. In his book Volume A of winter paintings, at first it wrote about Lohan at West Lake in St temple, then separately writes poems of famous poets in Tang and Song dynasty, with separately some long titles. My friend Yang Jun has enshrined and re-achieve it after a disaster, this is the poem: The ink landscape paintings often have highly accomplished monks, and in color paintings there are often bodhi trees. In the writings of the highly accomplished sages of the Tang and Song dynasties written on gold and stones (A book that was formerly written on metal and stone), there are also many classic stories about Buddhism. [18] Prajna monk refers to the Buddhist monk, the Bodhi tree is a synonym for Buddhism. Here, Qi Gong uses Buddhist things to compare the scene in the painting, and also thinks that the poems of famous masters in the Tang and Song dynasties are just like the Buddhist mandola rain, which can reflect his love for Buddhism and paintings. Therefore, he often used Buddhist language to give the paintings the finishing point. For example, in A picture of pine tree and spring compared to the Buddhist: "the sound of a long pine blowing in the wind is as solemn as the roar of a Buddhist lion. Strange stones stand there quietly, like monks meditating. If you're looking for the truth of the universe, the gifted always points outward. [19] The lion roar and diamond Zen in the poem are from Buddhist sutras. The lion roar was compared to Buddhism prestige, it sends out the loud sound, also vibrates the world. The headlamp said: when Buddha was born, he had one finger pointed at the sky and one finger at the ground. Roaring like a lion, it said: heaven and earth, I am the king. From the above discussion of the relationship between Buddhist allusions and painting, we can conclude that the painting environment and Zen meaning in Qi Gong's paintings are mutually integrated. He also used Buddhist principles to explain the painting, showing the great influence of Buddhism on the painting of Qi Gong. It is believed that Zen art is interlinked, and Buddhist allusions are often used to explain the ineffable profound truth in his 
paintings, which has a particular impact on painting remarks

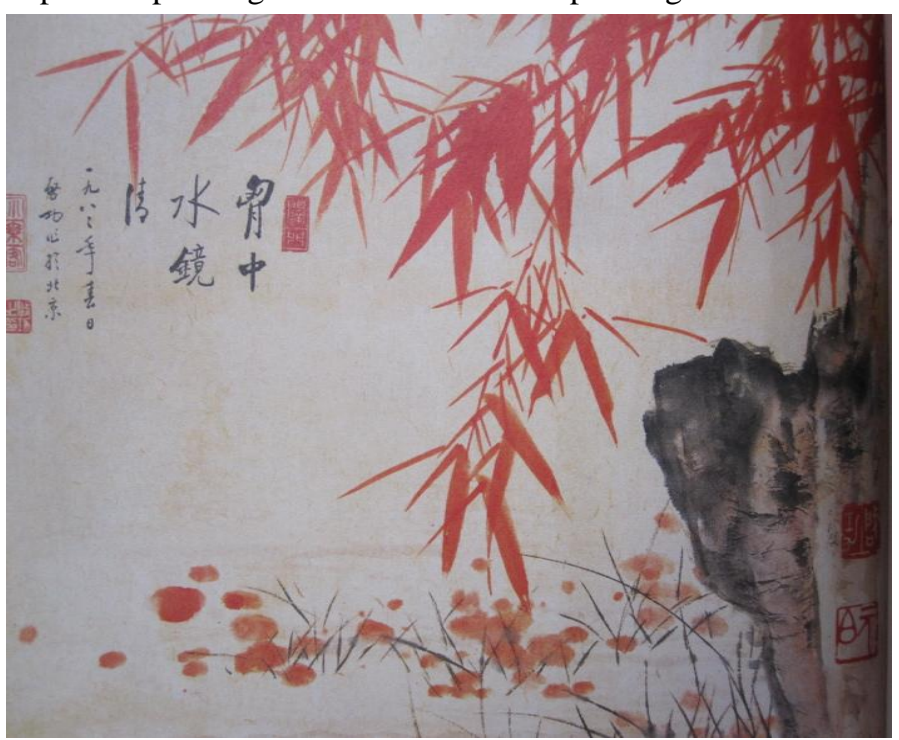

Fig. 4. Qi Gong's "Clear Mind as Water and Mirror".

\section{ZEN THEORY OF PAINTING AND STYLE OF PAINTING}

It is because of this idea that Zen art is interlinked. Therefore, Buddhist allusions are often used in the evaluation of paintings to explain the meaning of painting. In the "Writings on Yunshan painting" it said: It is Dong Qichang who is the master of expressing Zen using drawings. His words do not belong to traditional painting techniques but have their origins. Yi Yan believes that reading traditional books is to cover the eyes. If you only pay attention to the superficial meaning of the article, and do not intend to understand the essence behind it, the cowhide will be seen through." [20]Qi Gong uses Buddhist allusions in his poems to explain that Dong Qichang's painting comes from Zen. It is not from traditional painting methods but is a different branch. The poem appoints to Wei Yan master that "to let him look at the cowhide with great care and only draw a hole in the wall". He explained that: "Wei Yan was a monk in Qing Yuan faction. He forbidden others to study Buddhist classics: you should not watch the Buddhist classics. If you want to study the esoteric meaning of the sutra, you can only know it by meaning but without saying it. If you are stupid and only read the words, you will completely lose the deep spirit of the sutra. But he himself sometimes read the classics. His disciple asked him: you do not allow us to read, why would you read it? Master Wei Yan said: "I read it only to cover my eyes. However, if you read the classic, you will literally drill through it. A cowhide will be drilled though. He laughs at others reading literally but he reads it flexibly." [21]It can be seen that Qi Gong believes that painting can't be learned rigidly. If you stick to your old ways, you'll end up in a dead end. He said in on the painting of white lotus: "the high sounds shows the frogs only know how to tweet." [22] The frog tweeting is the language of the Zen. Its main meaning is that the frog can only jump but has no other abilities. It is compared to the rigid Zen which implies insufficient understanding, rigid and unfree learning, unlike him. Therefore, this characteristic of frogs is used to describe the fact that we can't be so well integrated in learning that we don't feel comfortable. Qi Gong often used Buddhism to evaluate paintings of past dynasties. In "painting one of the two poems of the peach," he said: "earlier I heard that Dao Wen monk has a high understanding in Zen and paintings." [23] In the poems, Dao Wen was not only good at Zen, but also highly qualified in paintings. His paintings are reflections of his thought of Zen. The peaches in the paintings have a deep meaning of Zen, like the Buddha's irrigation ceremony, which can be transmitted to people to increase their knowledge and ideas. He said in "five poems on donkeys painted by Huang Zhou": "my hands are not as golden as Buddhists in paintings, my feet are shorter than those of the donkeys. To understand the words of the highly accomplished monks that seemed unmeaningful, we have to read them from diverse aspects." [24]This has cited the ancient sentences "how can my hands compare to Buddhist's hands and how can my feet compare to Buddhist's feet?" to illustrate the principles of paintings. In the summer of 1985, he commented on the painting poem "On Dong Qichang's folded mountains and clouds": "This poem on the painting is the great one of the Zen and it greatly conforms to the scene. So, it was recorded here. There are elegant painting schools, all belonging to Hua Ting School, with light ink and light smoke, which has endless fun." [25]Qi Gong thinks Dong Qichang's paintings and poems are all conformed to Zen and are all inspiring. Landscape without bones: "There are indented flowers at the gate of the temple where Sengyou had become famous. Therefore, it is learned that paintings should be spared from the ink. And we should show the beauty of our country through the sunset." [26]Zhang Sengyou, a native of Suzhou. He is an assistant minister for Wuling King in Liang Tian prison, a painter at straight secret cabinet and is good at painting the Buddha. He once used painting methods of Tian Zhu (ancient India) on the gate of the Yicheng temple in Jiankang, and first used the method of concave-convex seasickness in his paintings. The figures of people and Buddists are vivid and lifelike. In a word, it is the 
influence of Buddhism on the painting realm of Qi Gong that caused the painting integrating Zen and painting, which has also reflected in the painting creation of Qi Gong.

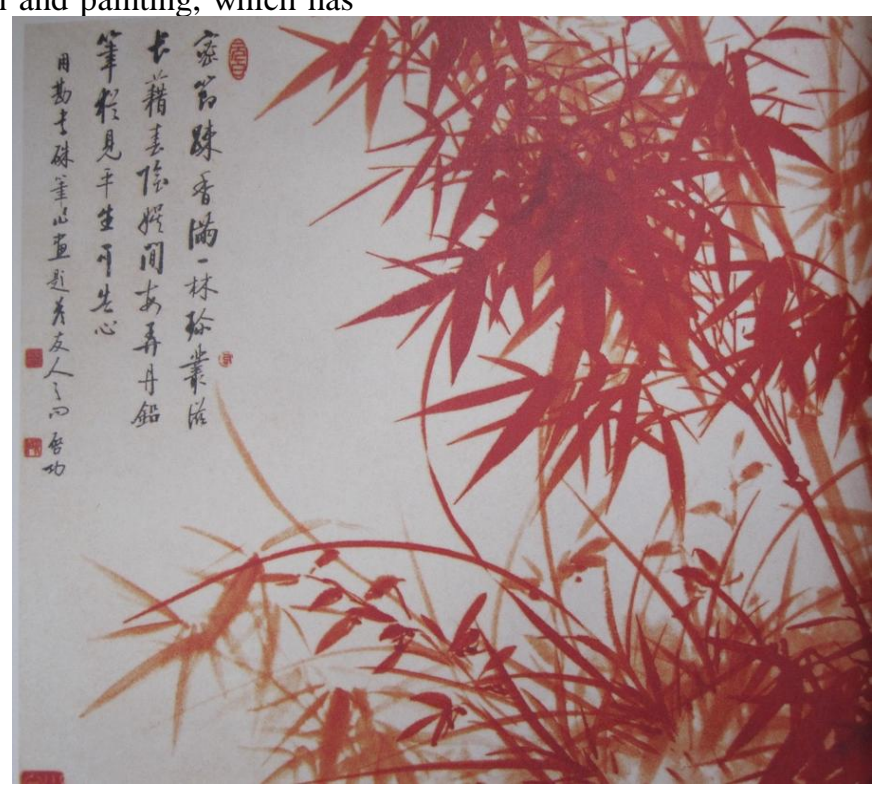

Fig. 5. Qi Gong's "Bamboo in Red".

About the painting style of Qi Gong, he said in the oral history of Qi Gong: "My paintings are typical literati paintings in the traditional sense, which are not intended to be realistic, but to show a kind of interest and realm." [27]The interest and state expressed by Qi Gong are inseparable from his painting thoughts of Zen. His paintings are ethereal and free. For example, the ink in the painting rose apples are purple complement the Zen in the poem "the rose apples are mostly purple, yet it cannot reflect on the broken cassock." "The paintings of Yuan Bai" on the other hand is clear, long, and bleak. It is like the jackdaws bursting out, its artistic conception profound. On his album title it said: "the author use graceful pencraft to show the morning breeze and the lingering moon." [28]The ink is clear and moist and the prospect is remote and bleak, leading a person to endless aftertaste. Especially the painting of bamboo and orchid in his old age, they are more unique, charming, clear and refined. In the "Clear Mind as Water and Mirror", Qi Gong integrates writings into the paintings. Through the red spots, the bamboos are red, grass lush, stones quiet, water wavering. The vivid artistic atmosphere can only be felt but not told. The composition of his paintings is changeful and the ink and strokes are vivid. It comes from the tradition but does not stick to the tradition. On why red bamboos were painted, Qi Gong explained in the oral history of Qi Gong: "Don't let others say I paint for evil intentions!' 'black paintings' can be used to refer to all kinds of paintings that can be criticized in a broad view. In a narrow sense, shortly after the cultural revolution, some people painted a batch of paintings, such as the owl with one eye open and one eye closed, which was officially named "black painting". Everyone who heard my explanation laughed. In fact, this is also involved in the painting problem. Are the ink bamboos painting true? Who has seen bamboo as black as ink? No matter it is black bamboo or red bamboo, it is the bamboo in the heart of the painter, and it is the artistic image of the painter to vent the breath in his chest." [29] This is exactly the reflection of the Zen master's idea that a living theory is not limited to external forms and traditional painting theories in his paintings, and it is just as Huang Miaozi said: "the work of Mr. Qi painting, landscape, orchid and bamboo, are extremely elegant." [30]In the June 2010 issue of People Weekly, "appreciation of Qi Gong's poetry, painting and calligraphy" was published to review his paintings: "The composition is rigorous, the technique is vivid, the color is bright, the charm is lingering. He is particularly good at landscape, bamboo and stone, and is of interest of traditional literary paintings... hen painting orchid and bamboo, the composition of the picture is strange out of being plain. He used the way of calligraphy to do the painting, making it clean and free from dust, thus is full of literary spirit." [31]The painting is clean and free from dust, which is the result of long-term exposure to Buddhism.

\section{CONCLUSION}

To sum up, Qi Gong loved painting deeply in his life. He was edified and trained in painting at an early age for family reasons. He painted a lot of works when he was young and worked as an art teacher at Fu Ren school. Although he later discontinued because he was listed in the right wing because of his painting, his love for painting remained. The theory of Buddhist allegory is often used by Qi Gong and a lot of Buddhist profound sentences are used in many painting poems to add splendor to his creation. Influenced by the Buddhist's unique aesthetics, the painting style is elegant and refined, which is often seen out of the plain. The composition of the picture is strange out of being plain. He used the way of calligraphy to do the painting, making it clean and free from dust, thus is full of literary spirit." The painting is clean and free from dust, which is the result of long-term exposure to Buddhism. 


\section{REFERENCES}

[1] Qigong: "one of the poems on the peach paintings ", in volume 6, Beijing: Beijing normal university publishing group, January 2009, page 173 .

[2] Qi Gong: oral history of qigong, volume 9, p. 52.

[3] Qi Gong: Autumn Chrysanthemum, vol. 11, p. 3. The following pictures are in the complete works of Qi Gong.

[4] Qi Gong: oral history of qigong, volume 9, p.65

[5] Qi Gong: oral history of qigong, volume 9, p.88

[6] Qi Gong: oral history of qigong, volume 9, p.135

[7] Qi Gong: oral history of qigong, volume 9, p.179

[8] Qi Gong: oral history of qigong, volume 9, p.181

[9] Qi Gong: oral history of qigong, volume 9, p.43

[10] Qi Gong: on the relationship between poetry, painting and calligraphy. In qigong collected 3, page 272.

[11] Qigong: "the 1,500th anniversary of Shaolin temple", volume 6, page 214.

[12] Qigong: The Act of Zen, volume 4, p. 93.

[13] Qi Gong: Remarks at a calligraphy exhibition of Su Shipeng and Ono Gishi, in volume 4 of the qigong collection, page 271.

[14] Qi Gong: " An Accidental Gift ", in Qi Gong collected 7, page 58.

[15] Qigong: "to herd the cows in the snow without a mark, archaic and lovely " in Qi Gong collected 6, p. 151.

[16] Dazheng, volume 47, all the publications of Dazheng, issued on April 8,13 . This is on page 533 .

[17] Qigong: Poems on Hanshan temple of suzhou, volume 6, page 235.

[18] In his book A volume of winter paintings, at first it wrote about Lohan at West Lake in St temple, then separately writes poems of famous poets in Tang and Song dynasty, with separately some long titles. My friend Yang Jun has enshrined and re-achieve it after a disaster, this is the poem. Vol. 6, p. 142.

[19] Qi Gong: the picture of the pines and the spring compared to plum blossom monk, volume 6, p. 91.

[20] Qi Gong: "the picture of mount Yun", volume 6, page 188.

[21] Qi Gong: Qi Gong's oral interpretation on poems, vol. 77, complete collection of qigong, volume 2, p. 278.

[22] Qi Gong: poems on the paintings of white lotus, vol. 6, p. 173.

[23] Qi Gong: two poems on the picture of rose apples. In Qi Gong collected 6, page 173 .

[24] Qi Gong: "Five donkeys painted by Huang Zhou", volume 6, page 117.

[25] Qi Gong: Poems on Dong Qichang's folded mountains and cloud, in Qi Gong Complete Book 5, page 1.

[26] Qi Gong: Landscape without bones, vol. 6, p. 177.

[27] Qi Gong: oral history of qigong, volume 9, p.179

[28] Qi Gong drawing: album page, vol. 12, p. 42.

[29] Qi Gong: oral history of qigong, volume 9, p.179

[30] Qi Gong: oral history of qigong, volume 9, p.179

[31] Gao Wenxiu. "Qi Gong poetry, painting and calligraphy," in people weekly, June 2010, page 85 